\title{
PERCEIVED MENTAL HEALTH AND LEARNING ENVIRONMENT OF STUDENTS IN NEPAL DURING COVID-19 OUTBREAK
}

\author{
Noora Shrestha \\ Assistant Professor, \\ Department of Mathematics and Statistics, \\ P.K. Campus, \\ Tribhuvan University, \\ Nepal \\ https://orcid.org/0000-0003-3905-6098
}

Article DOI: https://doi.org/10.36713/epra6333

\begin{abstract}
The COVID-19 pandemic has brought into attention the mental health of various affected populations including children and youth. The objective of the study was to assess the perceived mental health and learning environment of college students in Nepal during COVID-19 outbreak.

The college students enrolled in bachelor's degree completed a self-administered questionnaire survey. The students were approached through text messaging and email and selected with non-probability sampling during the pandemic. The study assessed information on demographic characteristics, academic difficulties, financial and family difficulties, and mental health issues with coping mechanism during the outbreak.

Descriptive findings revealed that the academic difficulties were more likely to be reported by high percentage of students. The students also described they were facing family and financial problems. High percentage of students was associated with depressive thought. To cope with anxiety and depressive thoughts, more than half students have pursued support from family and friends, helped themselves with self-management activities during the pandemic.

The COVID-19 pandemic situation is making a significant negative impact on mental health and learning environment of college students. The study suggests that health service providers and educators need to consider proactive measures to support the mental health and learning environment of students.
\end{abstract}

KEYWORDS: COVID-19, Mental Health, Learning Environment, Academic Difficulties, Financial Problems, Depressive Thought, Coping Mechanism, Self-management.

\section{INTRODUCTION}

The COVID-19 pandemic is causing more than 1.6 billion children and youth $(80 \%$ of the world's enrolled students) to be out of school in 161 countries as of March 28, 2020 (WHO, 2020). In the year 2020, most of the people were suffered from the corona virus outbreak. The government of Nepal announced suspension of all international flights followed by a countrywide full lockdown since 23 March 2020 because of which many people including children and youth spent their time staying at home (MoHP, 2020). This pandemic has greatest threats in the global education and created an enormous educational crisis, which might have an immediate impact on children and youth (WHO, 2020).

The previous literature examined that in short period of COVID-19 pandemic, the college students' lives have considerably changed with the new experience of life. Few literatures examined that the pandemic has potential to affect college students 
mentally, academically, financially, and socially. The studies also mentioned that some students felt difficulties with access to laptops and the Internet at home. Furthermore, students also reported that they were worried about the health of family members, exam, grades, and insecurity (Son et al., 2020; Al Ateeq et al., 2020; Kecojevic et al., 2020).

Some of the schools, colleges, and universities of Nepal used online tools to assure that lesson plans, videos, tutorial, and other resources are available for some students and probably, most teachers. These universities and colleges also facilitated learning material to be downloaded on a smartphone, which more students are likely to have. They trained the teachers to be familiar with online teaching and learning process. Government of Nepal communicated effectively with students, parents and teachers to provide guidelines, instructions and structure to the learning process, using content delivered by social media, radio or television (WHO, 2020; MoHP, 2020).

Nepal introduced the use of a computer in 1971 for the census. In 2014, the Internet penetration was $30.99 \%$ and $77.92 \%$ mobile telephone penetration in Nepal (ADB, 2017). In 2019, 34\% of the population in Nepal had access to the Internet (World Bank, 2020). In Nepal, many schools and colleges that are situated away from the district centers and city areas do not have technical support that could assist in installation and maintenance of computer technology. In addition, most of the schools and colleges do not have teachers with the technical abilities; they have to depend on external technical support.

The interruption of regular school and college has completely disrupted the lives of many students, their parents, and the teachers. To reduce this impact, many academic institutions prepared to move to online learning strategies with a lot of effort and challenges for teachers and parents. In low-income countries like Nepal, many students do not have a desk, books, Internet connectivity, electricity facility, a laptop at home, or supportive parents. Among the total users of Internet, $56 \%$ of Internet users are using mobile data (MoCIT, 2019). These issues many cause the negative effect on students' learning environment.

The COVID-19 pandemic situation has enforced the students into a new experience. The students' mental health in college education has been an increasing worry because of the action of the government of Nepal to close all educational institutions, postponing of all national level examinations and prohibiting the gathering of more people. Most of the students missed their regular school and college because going to school is not only about learning course books, but also about social connections and peer-to-peer communications. Since disease outbreaks can have mental health consequences, the present study explored the perceived mental health and learning environment among the students during the corona virus disease outbreak. It was assumed that the students has experienced online learning first time in their life

\section{METHOD}

The cross-sectional study was conducted using online questionnaire survey with 115 students studying in colleges of Lalitpur district of Nepal to realize the influence of the pandemic on their mental health and learning environment. In addition, the survey aimed to capture the ways that students have been coping with the mental health problems associated with the pandemic situation. The demographic characteristics, perceived mental health, and learning environment were assessed during COVID-19 occurrence period. These constructs were derived from existing literature identifying prominent factors affecting college students' mental health and learning environment (Son et al., 2020; Al Ateeq et al., 2020; Kecojevic et al., 2020). Feedback on the COVID-19's impact on the given statements of the questionnaire was elicited using a five-point scale: 1(strongly agree), 2(agree), 3(neutral), 4(disagree), and 5(strongly disagree). Participants were asked to elaborate on each response if they wish.

The government of Nepal had declared a nationwide lockdown and issued a stay-at-home order on $24^{\text {th }}$ March 2020 and closed all educational institutes. The colleges closed their regular classed and held all their classes virtually in response to the COVID-19 pandemic. The questionnaire survey was conducted about four months after the stay-at-home order in $1^{\text {st }}$ week of August 2020. Hence, the students were approached through text messaging and email with non-probability sampling during the pandemic. The students provided informed consent to participate in an anonymous survey and they were also informed about voluntary participation. Out of 115 , only 100 students completed the survey, resulting in a response rate of $87 \%$. The inclusion criteria for participation were that the student should have been enrolled in the college and age more than 18 years at the time of a survey. Using SPSS version 23, descriptive analysis examined the distribution of all variables of interest. The demographic information of students was expressed in frequency and percentage. The students' perception on learning environment, mental health, and coping with mental health strategies were presented in the table and bar diagram. 


\section{RESULTS AND DISCUSSION}

There were more male students $(60 \%)$ than female $(40 \%)$ who completed the self-administered questionnaire survey and the average age was 21.96 and standard deviation 1.97 years. The students were studying bachelor's degree in management in Lalitpur district of Nepal. The permanent residences of the participants were in province-1 (14\%), province-2 $(16 \%)$, Bagmati province $(22 \%)$, Gandaki province $(11 \%)$, Lumbini province $(6 \%)$, Karnali province $(13 \%)$, and Sudurpashchim province $(18 \%)$. The students mentioned their participation in online learning ranged from 1 to 5 hours, $38 \%$ of them spent 1-2 hours, 34\% spent 2-3 hours, $20 \%$ spent 3-4 hours, and $8 \%$ of students spent $4-5$ hours per day. All the students were involved in online classes and other interaction programs using a virtual meeting application 'Zoom.'

\subsection{Perceived Learning Environment}

The common learning environment challenges that the students face in pandemic are difficulty in online learning, worried about exam and grades, increasing assignment and project work, and distraction by social media.

\subsubsection{Students' Academic Difficulties During COVID-19}

The sudden outbreak of a COVID-19 trembled the entire country. This pandemic challenged the education system throughout the country and forced educators to shift to an online mode of teaching. Many colleges that were earlier hesitant to change their traditional pedagogical approach had no option but to shift entirely to online teaching learning with communication apps such as zoom video conferencing apps. Online learning was a new experience to the students and hence, they stated their concerns about sudden changes in teaching learning process, internet problems, technical issues with online applications, and difficulty of learning online.

Figure 1 demonstrates a majority of the students $(60 \%)$ were eagerly concerned about sudden changes in the teaching method, online learning, and course completion on time. Majority ( $80 \%)$ of them were likely to worry about their final exam. $72 \%$ of students revealed they were worried about their grades based on learning online. Due to lack of physical interaction with their teachers and other students and lack of library facilities, $57 \%$ of the students were worried about the completion of assignments. Not only this, many students (87\%) mentioned they were stressed because of project work and assignment submission date. $56 \%$ of the students agreed that there was lack of interactive learning environment on virtual classes. The students revealed very interesting facts that before COVID-19 pandemic, they wished to engage more time on computer, laptop, or mobile devices. During the pandemic period, they spent most of their time on the computer and mobile device. Now, $74 \%$ of the students expressed their agreement to the statement that doing everything sitting in front of a computer is a monotonous and bored. In addition, $46 \%$ of the students stated that they were experiencing distraction in learning process by social media, movies, and video games. $66 \%$ of the students responded that they were experiencing academic difficulties during the pandemic. 


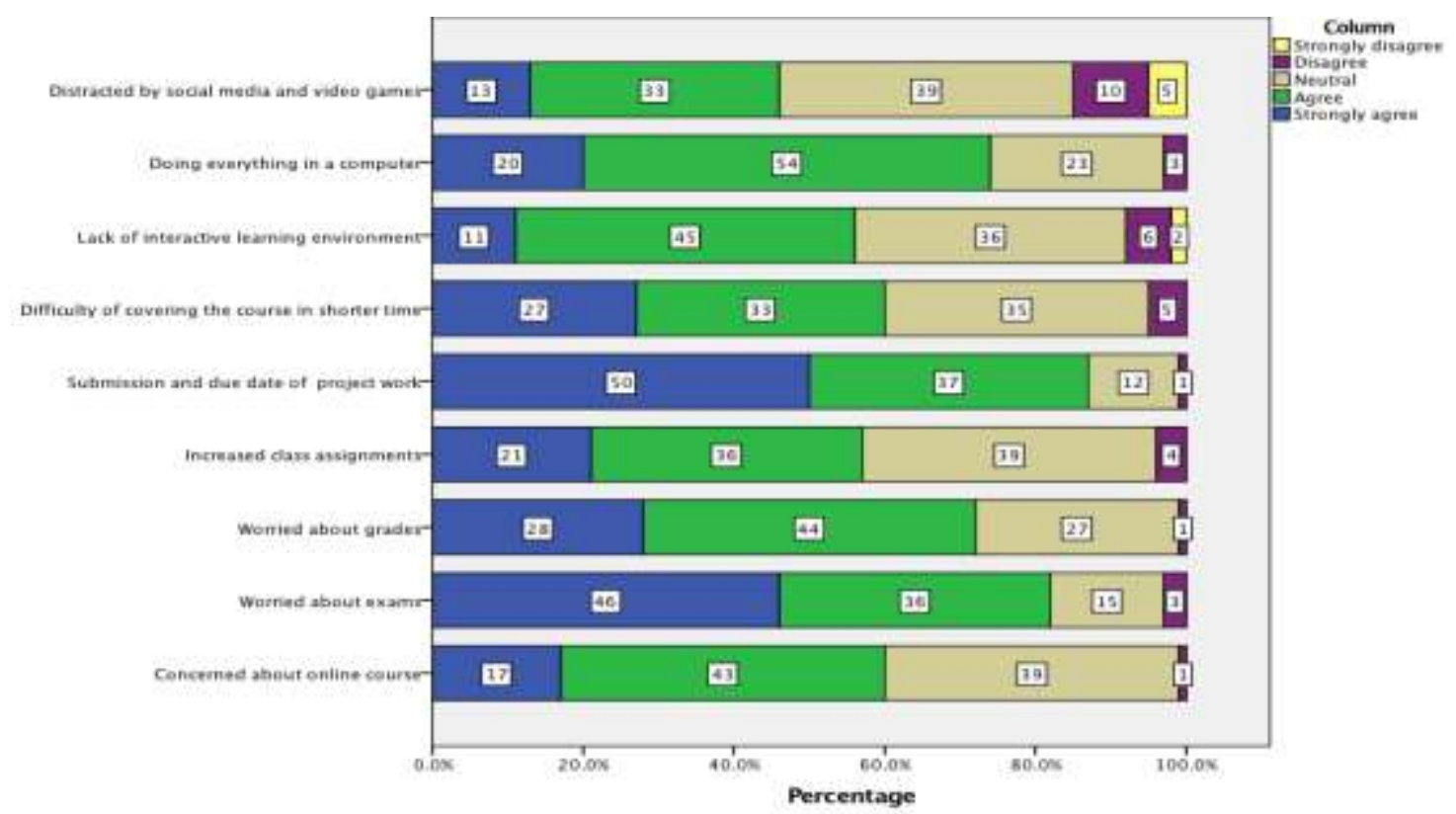

Figure 1. Students' Academic Difficulties

The median value was calculated for the statements that reflect the student's academic difficulties. The average students were neither agreed nor disagreed to the statement 'distracted by social media and video games', according to the median $(\mathrm{Md}=3)$ values. The median value $(\mathrm{Md}=2.0)$ for other statements indicates that majority of the students agreed that they have experienced difficulties in academic and learning environment during the COVID19 pandemic.

\subsubsection{Students' Financial and Family Difficulties During COVID-19}

Table 1 shows more than half of the students expressed their concerns about their financial situations being compressed by COVID-19. These students assumed that pandemic situation is likely to impact their own and family member's future employment opportunities. The reason for this is not receiving salary from the job of their parents and also a fear of loosing the job in the pandemic.

Although the participants are young students, $40 \%$ of them mentioned that they were worried about the health of their family members who were more vulnerable, such as grandparents with blood pressure, asthma, and diabetes. A majority of the students (51\%) stated that they were worried about their own health and dreaded to be infected by corona virus. $49 \%$ of students indicated difficulty in concentrating on online classes due to various sources of distraction at home such as conversation of family members, noise from the kitchen, and neighborhood.

Table 1. Students' Financial and Family Difficulties During COVID-19

\begin{tabular}{|l|c|c|c|c|c|c|}
\hline Factors & $\mathbf{1}$ & $\mathbf{2}$ & $\mathbf{3}$ & $\mathbf{4}$ & $\mathbf{5}$ & Median \\
\hline Financial difficulties & $26 \%$ & $31 \%$ & $25 \%$ & $11 \%$ & $7 \%$ & 2 \\
\hline Worry about health of family member & $13 \%$ & $27 \%$ & $32 \%$ & $20 \%$ & $8 \%$ & 3 \\
\hline Distractive environment to study & $13 \%$ & $36 \%$ & $40 \%$ & $9 \%$ & $2 \%$ & 3 \\
\hline Disruption to eating pattern & $34 \%$ & $37 \%$ & $20 \%$ & $9 \%$ & $0 \%$ & 2 \\
\hline Disruption to the outdoor activities & $19 \%$ & $22 \%$ & $32 \%$ & $24 \%$ & $3 \%$ & 3 \\
\hline Changes in the living environment & $8 \%$ & $29 \%$ & $30 \%$ & $25 \%$ & $8 \%$ & 3 \\
\hline Worry about infected & $13 \%$ & $38 \%$ & $28 \%$ & $18 \%$ & $3 \%$ & 2 \\
\hline
\end{tabular}

(1-strongly agree, 2- agree, 3-neutral, 4- disagree, 5- strongly disagree)

It is very interesting to know that $71 \%$ of students realized disruptions to eating pattern such as uneven times of eating and omitting meals. Some of them mentioned that they over ate food while involved 
in cooking. On the other hand, $9 \%$ students reported that they were not having problems in their dietary pattern, as they were eating healthy food at home, not a junk food as usual.

Majority of the students revealed that they stayed with their families, so they could adjust with change in environment during the pandemic whereas $37 \%$ of them had difficulties to cope with the new environment. The median values in the table 1 , shows that the average agreement of the students to the statement financial difficulties, disruption to eating pattern, and worry about infected during COVID-19 pandemic.

\subsection{Perceived Mental Health}

The common mental health challenges that the students face in pandemic are depressive thought such as depression, mood swing, eating disorders, anxiety, loneliness, and insecurity. These factors represent only some of the prevalent mental health problems experienced by the college students in the pandemic, which they consider as a part of the college life.
Symptoms for depression and anxiety differ from person to person but when a college life of a student is disrupted, depressive thoughts crosses the line to become a medical condition.

\subsubsection{Students' Depressive Thoughts During COVID-19}

To assess the impact of the COVID-19 pandemic on students' mental health, few statements were included in the questionnaire and students in the questionnaire and students are asked to rate their perception and presented in table 2. Out of 100 students, 59\% agreed that they were suffering from anxiety due to the COVID-19 pandemic, whereas $11 \%$ mentioned that they did not have anxiety and $30 \%$ of them were neither agreed nor disagreed. Major contributors to the depressive thoughts were depression (48\%), mood swing (70\%), sleep disorder $(32 \%)$, insecurity (53\%), difficulty with concentration (68\%), loneliness $(60 \%)$, overthinking $(56 \%)$, and social isolation (44\%).

Table 2. Students' Depressive Thoughts During COVID-19

\begin{tabular}{|l|c|c|c|c|c|c|}
\hline Factors & $\mathbf{1}$ & $\mathbf{2}$ & $\mathbf{3}$ & $\mathbf{4}$ & $\mathbf{5}$ & Mode \\
\hline Anxiety & $13 \%$ & $46 \%$ & $30 \%$ & $11 \%$ & $0 \%$ & 2 \\
\hline Depression & $21 \%$ & $27 \%$ & $29 \%$ & $15 \%$ & $8 \%$ & 3 \\
\hline Mood Swing & $20 \%$ & $50 \%$ & $13 \%$ & $17 \%$ & $0 \%$ & 2 \\
\hline Sleep Disorder & $15 \%$ & $17 \%$ & $45 \%$ & $23 \%$ & $0 \%$ & 3 \\
\hline Insecurity & $23 \%$ & $30 \%$ & $28 \%$ & $17 \%$ & $2 \%$ & 2 \\
\hline Difficulty with concentration & $26 \%$ & $42 \%$ & $21 \%$ & $9 \%$ & $2 \%$ & 2 \\
\hline Loneliness & $22 \%$ & $38 \%$ & $23 \%$ & $17 \%$ & $0 \%$ & 2 \\
\hline Overthinking & $21 \%$ & $35 \%$ & $24 \%$ & $20 \%$ & $0 \%$ & 2 \\
\hline Social Isolation & $17 \%$ & $27 \%$ & $29 \%$ & $25 \%$ & $2 \%$ & 3 \\
\hline
\end{tabular}

(1-strongly agree, 2- agree, 3-neutral, 4- disagree, 5- strongly disagree)

The modal values on the table 2 shows that there are students whose perception are neutral for the factors depression, sleep disorder, and social isolation. They faced this kind of pandemic first time in their life and could not figure out what was going on in their life. The data depict a major problem faced by students was depressive thoughts.

\subsubsection{Coping with Mental Health During COVID-19}

To cope with the mental health difficulties foisted by COVID-19, the students were trying to overcome with this situation using various selfmanagement activities, and seeking help from family members. $41 \%$ of the students explained that they were involved in meditation and simple yoga exercises to help themselves cope with mental health problems during the pandemic. Many of the students used positive coping methods such as regular exercises $(50 \%)$, stay calm (46\%), stay alone and enjoy (59\%), and ignoring the news (56\%) about COVID-19.

Majority of the students (73\%) used relaxing method, for instant, listening to the music and paying video games. Half of the students $(50 \%)$ declared that interaction with parents, sharing feelings with the family member and online discussion with the friends was the best way to deal with their mental health and other issues. The students also helped themselves to manage with mental health difficulties cooking variety of food, involving in other household tasks, playing indoor games, and sleeping longer. More than half $(55 \%)$ of the participants were trying to cope with mental health issues with self-management activities during the pandemic. 


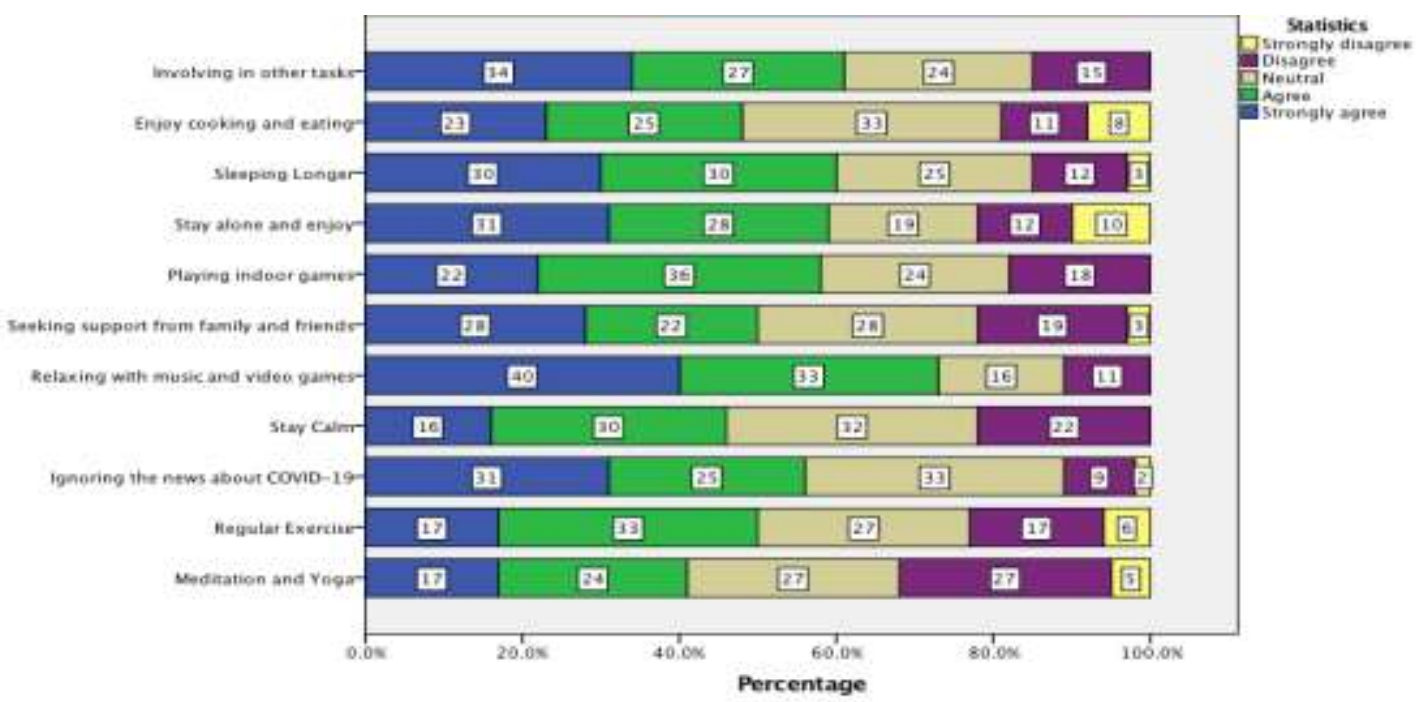

Figure 2. Coping with Mental Health

The previous studies showed that COVID-19 outbreaks influenced students' mental health and wellbeing. The studies also revealed that most of the students were suffering from stress, anxiety, depression, and loneliness during pandemic. The findings of this study are comparable to other national and international studies that were conducted during the pandemic (Dangal et al., 2020; Son et al., 2020). Most of the studies selected young students as a sample with convenient sampling method. The questionnaire items were measured by five-point Likert scale. The findings showed that online learning was associated with stress, financial difficulties, and academic difficulties of the students. In addition, the literatures attempted to disclose the coping mechanism with selfmanagement activities such as breathing exercise, relaxing hobbies, and psychological counseling. A high level of stress was observed among the female students comparing to the male (Al Ateeq et al., 2020; Kecojevic et al., 2020).

The present study was conducted during the pandemic with the online survey and hence, this study acknowledge some limitations. The non-probability sampling used for the online survey of a sample limits the generalizability of the results. The study findings were based on the self-reported questionnaire survey that may affect the participations response analysis. The cross-sectional study design prohibits the ability to make causal inferences, as data represents a single moment in time.

\section{CONCLUSION}

The study discussed the college students' perceived learning environment and mental health during COVID-19 pandemic. This pandemic situation is making a significant negative impact on mental health and learning environment of college students. The present study may shed light on the existing mental health problems among students in Nepal and suggest that health service providers and educators need to consider proactive measures to support the mental health and learning environment of students. Proactive efforts to support students' wellbeing, ensuring they have self-management skills to handle the pandemic situation are desirable. The results of this study could be used as a baseline and further studies can be conducted with probability sampling, more sample size, and longitudinal research design to examine other relevant constructs.

\section{REFERENCES}

1. WHO. (2020). Maintaining essential health services: Operational guidance for the COVID-19 context interim guidance. World Health Organization.

https://www.who.int/publications/i/item/WHO2019-nCoV-essential-health-services-2020.1

2. MoHP. (2020). Health sector emergency response plan: COVID-19 pandemic. Government of Nepal, Ministry of Health and Population. https://publichealthupdate.com/health-sectoremergency-response-plan-mohp-nepal

3. Son, C., Hegde, S., Smith, A., Wang, X., \& Sasangohar, F. (2020). Effects of COVID-19 on college students' mental health in the United States: Interview survey study. Journal of Medical Internet Research, 22(9), e21279. https://doi.org/10.2196/21279.

4. AlAteeq, D.A., Aljhani, S., \& AlEesa, D. (2020). Perceived stress among students in virtual classrooms during the COVID-19 outbreak in KSA. 
Journal of Taibah University Medical Sciences, 15(5),398-403. doi: 10.1016/j.jtumed.2020.07.004.

5. Kecojevic, A., Basch, D.H., Sullivan, M., \& Davi, N.K. (2020). The impact of the COVID-19 epidemic on mental health of undergraduate students in New Jersey, Cross-sectional study. PLos ONE, 15(9), e0239696. doi:10.1371/journal.pone.0239696.

6. WHO. (2020). WHO Nepal Situation Updates on COVID-19. World Health Organization. https://www.who.int/nepal/news/detail/19-01-2021who-nepal-situation-update.

7. ADB. (2017). Innovative strategies for accelerated human resource development in South Asia information and communication technology for education: Special focus on Bangladesh, Nepal and Sri Lanka. Asian Development Bank: Philippines.

8. World Bank. (2020). Individuals using Internet (\% of population) Nepal. https://data.worldbank.org/indicator/IT.NET.USER .ZS? locations $=N P$

9. MoCIT.(2019). Digital Nepal framework: Unlocking Nepal's growth framework. Government of Nepal, Ministry of Communication and Information Technology.

10. Dangal, M.R. \& Bajracharya, L. S. (2020). Students' anxiety experiences during COVID-19 in Nepal. Kathmandu University Medical Journal. COVID-19 special issue, 70(2), 53-57. 